\title{
Environmental TEM study of the dynamic nanoscaled morphology of NiO/YSZ during reduction
}

Simonsen, Søren Bredmose; Agersted, Karsten; Hansen, Karin Vels; Jacobsen, Torben; Wagner, Jakob Birkedal; Hansen, Thomas Willum; Kuhn, Luise Theil

Published in:

Applied Catalysis A: General

Link to article, DOI:

10.1016/j.apcata.2014.10.045

Publication date:

2015

Document Version

Peer reviewed version

Link back to DTU Orbit

Citation $(A P A)$ :

Simonsen, S. B., Agersted, K., Hansen, K. V., Jacobsen, T., Wagner, J. B., Hansen, T. W., \& Kuhn, L. T. (2015). Environmental TEM study of the dynamic nanoscaled morphology of $\mathrm{NiO} / Y S Z$ during reduction. Applied

Catalysis A: General, 489, 147-154. https://doi.org/10.1016/j.apcata.2014.10.045

\section{General rights}

Copyright and moral rights for the publications made accessible in the public portal are retained by the authors and/or other copyright owners and it is a condition of accessing publications that users recognise and abide by the legal requirements associated with these rights.

- Users may download and print one copy of any publication from the public portal for the purpose of private study or research.

- You may not further distribute the material or use it for any profit-making activity or commercial gain

- You may freely distribute the URL identifying the publication in the public portal 


\title{
Environmental TEM study of the dynamic nanoscaled morphology of NiO/YSZ during reduction
}

Søren Bredmose Simonsen ${ }^{\mathrm{a}, *}$, Karsten Agersted $^{\mathrm{a}}$, Karin Vels Hansen ${ }^{\mathrm{a}}$, Torben Jacobsen ${ }^{\mathrm{a}}$, Jakob Birkedal Wagner ${ }^{\mathrm{b}}$, Thomas Willum Hansen ${ }^{\mathrm{b}}$, Luise Theil Kuhn ${ }^{\mathrm{a}}$

${ }^{a}$ Department of Energy Conversion and Storage, Technical University of Denmark, DK-4000 Roskilde, Denmark

${ }^{\mathrm{b}}$ Center for Electron Nanoscopy, Technical University of Denmark, DK-2800 Kgs. Lyngby, Denmark

*Corresponding author, email address: sobrs@dtu.dk, phone: +45 20120611 (Søren Bredmose Simonsen)

\section{Keywords:}

Nickel oxide reduction, NiO, YSZ, SOFC, SOEC, in situ TEM, ETEM, autocatalysis

\begin{abstract}
The reduction of a metal oxide is often a critical preparation step for activating catalytic behavior. This study addresses the reduction process of $\mathrm{NiO}$ in pure form and in a composite of NiO/yttriastabilized zirconia (YSZ) in hydrogen relevant for solid oxide electrochemical cells by comparing results from environmental transmission electron microscopy (ETEM) with thermogravimetric analysis (TGA). The temperature dependent reduction profiles obtained from TGA confirm an inhibitive effect from YSZ on the NiO reduction. The ETEM images show the growth of $\mathrm{Ni}$ in decaying $\mathrm{NiO}$ and reveal the nanoscale morphological changes such as pore formation in $\mathrm{NiO}$ above $280^{\circ} \mathrm{C}$ and densification and collapse of the pore structures above $400^{\circ} \mathrm{C}$. The accelerated $\mathrm{Ni}$ front in $\mathrm{NiO}$ illustrates the autocatalysis of the reaction. A rapid temperature ramping from room temperature to $780^{\circ} \mathrm{C}$ in hydrogen in 1 second resulted in immediate morphological changes at the nanoscale from dense $\mathrm{NiO}$ to dense $\mathrm{Ni}$. The analysis suggests that the inhibitive effect of YSZ on the $\mathrm{NiO}$ reduction reaction is not due to a direct local interaction between YSZ and NiO, but instead due to gas and/or mass transport limitations.
\end{abstract}

\section{Introduction}

The reduction of metal oxides is a typical step in the preparation of the active metal surfaces for various catalyst systems. Conditions of the reduction process, such as temperature, reduction time, gas composition, gas flow and pressure, are important for optimizing the catalyst performance [1,2]. 
Understanding the metal oxide reduction process is therefore important in order to be able to optimize the catalyst activity. The reduction of nickel-based catalysts used for e.g. oxidation [3], methanation [4] and ammonia decomposition [5] has been extensively studied [2,6-16]. The reduction of $\mathrm{NiO}$ with $\mathrm{H}_{2}$ occurs without any intermediate phase [8] and can be described by the relatively simple formula:

$$
\mathrm{NiO}(\mathrm{s})+\mathrm{H}_{2}(\mathrm{~g})->\mathrm{Ni}(\mathrm{s})+\mathrm{H}_{2} \mathrm{O}(\mathrm{g})
$$

The loss of oxygen during reduction leads to a volume decrease by $41 \%$ resulting in a restructuring of the overall morphology of the solid and can lead to pore formation in the Ni [17-19]. A delay in the reduction onset, a so-called incubation or induction period is reported, which decreases with reaction temperature $[6,8,10,12]$ and increasing number of defects on the NiO surface [10]. It has been suggested that dissociative adsorption of hydrogen, which is a necessary initiation step for the $\mathrm{NiO}$ reduction, preferentially takes place at $\mathrm{NiO}$ surface oxygen vacancies $[8,10]$. The reduced $\mathrm{Ni}$ surface will act as a catalyst for dissociative $\mathrm{H}_{2}$ adsorption and it has been suggested that the reduction of $\mathrm{NiO}$ will be autocatalytically accelerated in the vicinity of a Ni surface [6]. On the contrary, the produced $\mathrm{H}_{2} \mathrm{O}$ influences the reaction rate negatively, possibly by poisoning of the active sites for $\mathrm{H}_{2}$ adsorption $[6,18]$. In addition it has been reported that the reaction rate scales with the $\mathrm{H}_{2}$ pressure $[8,10,17]$.

Ni catalysts are often integrated into an oxide matrix and for such systems the reduction of $\mathrm{Ni}$ oxide can be slower than for the pure $\mathrm{NiO}[7,12]$. An important example is the porous composite of $\mathrm{Ni}$ and yttria-stabilized zirconia (YSZ), which is the state-of-the-art anode in commercial solid oxide fuel cells (SOFC) and cathode in solid oxide electrolysis cells (SOEC) [11-16]. In these electrochemical cells Ni simultaneously acts as an electron conductor and catalyst for splitting the adsorbed reactive gases, while YSZ acts as an oxygen ion conductor. The porous Ni/YSZ is typically prepared from powder mixtures of $\mathrm{NiO}$ and YSZ [13,14,16], sintered into a dense structure and finally reduced during start-up of the SOFCs/SOECs, typically around $800^{\circ} \mathrm{C}$ $[13,15,16]$. The overall performance of SOFCs/SOECs depends on the initial reduction step and the related morphology $[12,20]$ and several studies have focused on the reduction of $\mathrm{NiO}$ in mixtures with YSZ [12,15,16,19,20]. It is reported that YSZ inhibits the reduction of $\mathrm{NiO}[11,12,16]$, but the reason for the inhibitive effect of YSZ is not clear. Linear kinetics in the reduction of dense $\mathrm{NiO} / \mathrm{YSZ}$ samples at temperatures below $700^{\circ} \mathrm{C}$ suggests that the reaction is interface controlled and therefore not limited by gas transport in the produced porous Ni $[13,16,18]$. On the other hand, 
YSZ has been suggested to act as transport barrier for the reaction front inside the NiO/YSZ matrix [12]. Increasing sintering temperatures leads to a stronger inhibitive effect of YSZ, and the effect has therefore previously been explained by formation of $\mathrm{NiO}$ crystallites incorporated in YSZ and formation of a metastable solid solution of NiO in YSZ [16]. It has also been suggested that the reduction rate at the $\mathrm{NiO}-\mathrm{YSZ}$ interfaces is relatively low due to a $\mathrm{NiO}$-YSZ chemical interaction [16] or due to a slow Ni nucleation [12].

Techniques, such as thermogravimetric analysis (TGA) [12,14], thermomechanical analysis (TMA) [14], temperature programmed reduction (TPR) [11], X-ray diffraction (XRD) [10,11,15], X-ray photoelectron spectroscopy (XPS) $[8,10]$ and Auger spectroscopy $[8,10]$ have given significant insight into the $\mathrm{NiO}$ reduction process. In addition, local information has been obtained using post mortem electron microscopy $[12,13,14,17,18]$. However, nanoscale dynamics, such as initiation of the reduction, crystal growth/decay or morphological changes of $\mathrm{NiO}$ and $\mathrm{Ni}$ during reduction can only be indirectly probed with these techniques. It can also be difficult to separate the different structural parameters that simultaneously influence the reduction process, such as local composition, particles sizes, mobility of the solids and pathways for gas transport in the samples $[17,18]$. ETEM offers a localized study with atomic resolution in a gas environment at elevated temperatures [21-24]. ETEM has been used to study the $\mathrm{NiO}$ reduction reaction at the nanoscale [19,25-28] and has given insight into e.g. the mobile species (Ni-atoms [25] or O-atoms [19]) and the initial Ni formation at the $\mathrm{NiO}$ surfaces [24].

The present work is a comparative study of the reduction of pure $\mathrm{NiO}$ and NiO/YSZ with a) TGA to describe the overall temperature dependency of the reaction for macroscopic samples and with b) ETEM to probe the sample at the nanoscale during exposure to $\mathrm{H}_{2}$ at elevated temperatures. The goal of the study is firstly to address the apparent inhibitive influence from YSZ on the $\mathrm{NiO}$ reduction and secondly to describe the morphological changes of the $\mathrm{NiO} / \mathrm{YSZ}$ during reduction at different temperature ramping rates for temperatures up to $780^{\circ} \mathrm{C}$.

\section{Experimental}

\subsection{Catalyst preparation}

An SOFC anode (SOEC cathode) consisting of 56 wt.\% NiO and 44 wt.\% YSZ with 8 mol\% yttria was prepared by tape casting from mixed powder of $\mathrm{NiO}$ (Novamet Specialty Products Corp.) and YSZ (Tosoh Corporation) as described in detail in reference [29]. A reference sample was prepared 
by tape casting the pure YSZ. An additional reference sample was prepared by die pressing a pellet from the pure $\mathrm{NiO}$ powder. All of these samples were sintered in air at $1350^{\circ} \mathrm{C}$ for 3 hours. In one experiment the dense $\mathrm{NiO}$ /YSZ sample was used without further preparations, but for other experiments the samples were ground into a fine powder in a mortar. In addition, the raw $\mathrm{NiO}$ powder was used as a non-sintered reference sample.

\subsection{Catalyst characterization}

TGA was performed on all samples on a Netzsch STA 409CD Thermobalance. The powder samples were spread out on the surface of a wok-type sample holder mounted vertically in the test chamber. $50 \mathrm{mg}$ of YSZ and NiO/YSZ powder was used. $30 \mathrm{mg}$ of the pure NiO powder was used, to assure a similar amount of $\mathrm{NiO}$ was used in both sample types. In addition to the powder samples, a piece of $30 \mathrm{mg}$ of the sintered dense $\mathrm{NiO} / \mathrm{YSZ}$ sample was placed in a flat holder with a diameter of $17 \mathrm{~mm}$ (Netzsch 445.240). The TGA experiments were performed in a flow of 50 $\mathrm{Nml} / \mathrm{min} 9 \% \mathrm{H}_{2} / \mathrm{N}_{2}$ (Air Liquide: H4.6; N6.0). The temperature was initially ramped from room temperature to $150^{\circ} \mathrm{C}$ at $10^{\circ} \mathrm{C} / \mathrm{min}$ and held at this temperature for 2 hours to dry the samples prior to the actual reduction experiment. The reduction experiment was performed by ramping the temperature to $1200^{\circ} \mathrm{C}$ at $1^{\circ} \mathrm{C} / \mathrm{min}$.

Using a JEOL 3000F equipped with a 300kV FEG, a scanning unit (STEM) and a high-angle annular dark-field (HAADF) detector, ex situ STEM of the NiO/YSZ powder was carried out to determine the spatial distribution of the different elements in the sample at the nanoscale. Energydispersive X-ray spectroscopy (EDS) was carried out for compositional analysis by using an Oxford Instruments detector with an ultra-thin window. The analysis was performed using the Inca software. The ground powder was dispersed in ethanol and a droplet of the suspension was placed on a standard TEM copper grid.

The ETEM experiments were performed using a Titan 80-300 (FEI) electron microscope equipped with a differentially pumped environmental cell [30]. The microscope was operated with a primary electron energy of $300 \mathrm{keV}$. In the electron microscope, the powder samples were exposed to 2 mbar $\mathrm{H}_{2}$ (AGA 6.0). The powder samples were ground with ethanol and droplets of the suspension were deposited on the surface of MEMS thermal E-chips (Protochips Inc.) and the samples were allowed to dry in air at room temperature before inserting the TEM holder. The chips used for the experiments were either with or without a carbon support. The chips were mounted in an Aduro 300 
heating holder (Protochips Inc.) facilitating the heating of the samples in the gaseous environment. The temperature calibration of the heating holder is described in detail in the supplementary materials appendix A.

\subsection{Critical remarks on the ETEM analysis}

Before performing the actual reduction experiments it is necessary to determine whether artifacts are induced by the electron beam. Indeed it has been reported that $\mathrm{NiO}$ can be reduced by a focused $100 \mathrm{kV}$ electron probe in vacuum [9]. The $\mathrm{NiO} / \mathrm{YSZ}$ sample was exposed to $2 \mathrm{mbar} \mathrm{H}_{2}$ and a constant exposure to the electron beam with a beam current density of ca. $600 \mathrm{e}^{-} / \mathrm{nm}^{2} \mathrm{~s}$ for $30 \mathrm{~min}$ at room temperature. No structural changes of the NiO/YSZ were observed after this treatment, except that a layer of amorphous carbon builds up on the sample surface. The actual reduction experiments were performed at approximately the same beam current density, but with a lower total dose since the electron beam was blanked between image acquisitions. For the longest experiment the estimated total electron beam exposure was $15 \mathrm{~min}$. In addition, comparison of areas followed over time with previously unexposed areas showed no characteristic structural differences. It is therefore unlikely that the dominating structural changes of the samples during the reduction experiments are due to the electron beam.

Since the TEM images are two-dimensional projections of the three-dimensional sample, the TEM image analysis can be challenging. For the present powder samples, it is easier to observe the initiation of the reduction process in thin regions and at the edges of the particles than at thicker regions and at surfaces normal to the electron beam. Also, overlapping $\mathrm{NiO}$ and YSZ grains with no contact could be mistaken for real NiO-YSZ interfaces. Further, since the sample temperature is controlled via the heat conducting support, heat gradients from the support and out through the sample cannot be ruled out. In addition, some of the sintered NiO-YSZ interfaces are possibly broken during sample preparation and it is not possible to determine with certainty whether an observed interface represents a sintered NiO-YSZ interface or NiO and YSZ particles bound by van der Waal forces. Two strategies in the analysis are followed to compensate for these issues: 1) For the image analysis, several imaged areas are compared to increase the probability of studying the sintered interfaces and variations of sample geometry. Specifically, six different areas with one or more NiO-YSZ interfaces were analyzed. 2) The ETEM image analysis, focusing on relatively few NiO-YSZ grains and interfaces, is compared to the ETEM diffraction analysis, which is based on a larger sample area (ca. $15 \mu^{2}$ ) with many NiO-YSZ grains and interfaces. 


\section{Results}

\subsection{TGA results}

From TGA the temperature dependencies of the $\mathrm{NiO}$ reduction reaction were obtained (Fig. 1). The mass of the non-sintered $\mathrm{NiO}$ powder (Fig. 1, full black line) decreases relatively fast above $300^{\circ} \mathrm{C}$. This is interpreted as loss of oxygen by referring to the reaction described by Eqn. 1 . At $350^{\circ} \mathrm{C}$, the non-sintered $\mathrm{NiO}$ powder has lost $85 \%$ of its oxygen, the reduction reaction rate (the slope of the curve) slows down and the mass decreases until reaching $79 \%$ of the initial mass at $\mathrm{ca} .800^{\circ} \mathrm{C}$, corresponding to full reduction. The trend of the sintered NiO powder (Fig. 1, dashed black line) is similar to the non-sintered powder, but with a slightly higher initial reduction temperature. According to images recorded by scanning electron microscopy (not presented) the mean particle size of 100 random particles for the sintered NiO powder is $3 \mu \mathrm{m}$ in diameter, while $0.7 \mu \mathrm{m}$ for the non-sintered $\mathrm{NiO}$ powder. Since the total $\mathrm{NiO}$ surface area depends on the mean particle size, a lower reduction temperature could have been expected for the non-sintered powder, but it is observed that the size effect is relatively weak.

Similar to the pure $\mathrm{NiO}$ samples, full reduction of the mixed $\mathrm{NiO} / \mathrm{YSZ}$ powder is reached at $800^{\circ} \mathrm{C}$, but the reduction process is generally slower (Fig. 1 full grey line). The onset temperature is ca. $280^{\circ} \mathrm{C}$, which is slightly below that of pure $\mathrm{NiO}$ powders. The pure YSZ powder has a constant mass for all temperatures and is hence not reduced (Fig. 1, dotted light grey line). The mass loss observed for the $\mathrm{NiO} / Y S Z$ powder is therefore attributed solely to the $\mathrm{NiO}$. The mass loss curve for the dense of NiO/YSZ sample (Fig. 1, dashed grey line) agrees with reports from similar experiments on dense samples [11,12,14]. It also shows the same overall trend as observed for the $\mathrm{NiO} / \mathrm{YSZ}$ powder, except that the onset of the reaction is shifted up by ca. $100^{\circ} \mathrm{C}$. 


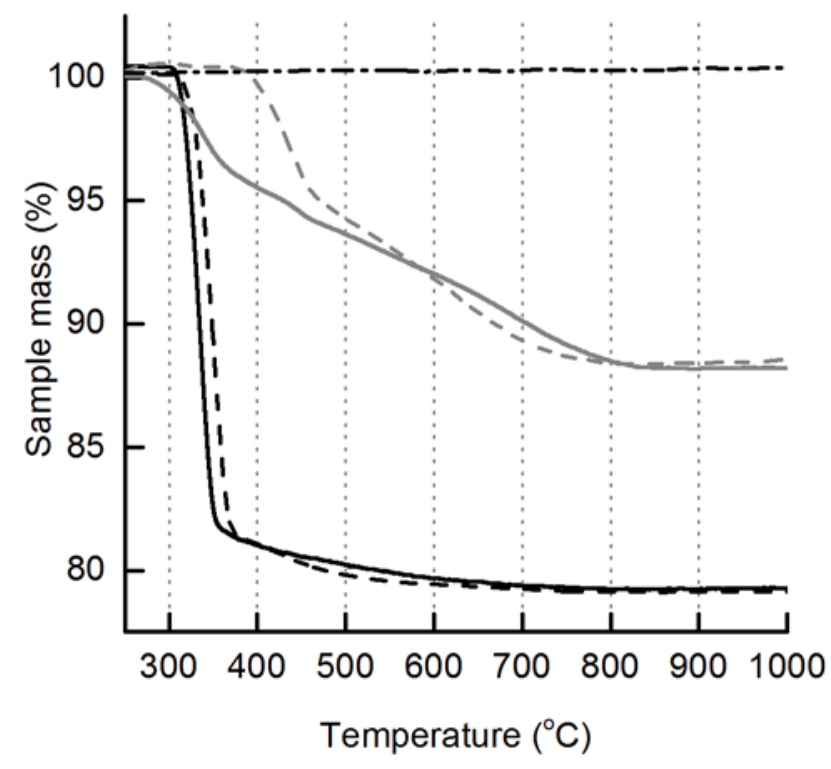

Fig. 1: The mass as a function of temperature for non-sintered $\mathrm{NiO}$ powder (solid black), NiO powder ground after sintering at $1350^{\circ} \mathrm{C}$ (dashed black), $\mathrm{NiO} / \mathrm{YSZ}$ powder ground after sintering at $1350^{\circ} \mathrm{C}$ (solid grey), a dense piece of the $\mathrm{NiO} / \mathrm{YSZ}$ sintered at $1350^{\circ} \mathrm{C}$ (dashed grey) and YSZ powder ground after sintering at $1350^{\circ} \mathrm{C}$ (black dash-dot) during exposure to $9 \% \mathrm{H}_{2} / \mathrm{N}_{2}$ at a constant ramping rate of $1^{\circ} \mathrm{C} / \mathrm{min}$.

\subsection{STEM-EDS results}

As described in the introduction, it has been suggested that the inhibitive effect of YSZ could be partly explained by the formation of $\mathrm{NiO}$ crystallites incorporated in YSZ at high sintering temperatures and of a metastable solid solution of $\mathrm{NiO}$ in YSZ [16]. Previous studies have shown that nickel can enter YSZ during the sintering process [31,32]. STEM-EDS elemental maps of the $\mathrm{NiO} / Y S Z$ powder sample were recorded in order to determine the spatial distribution of the $\mathrm{Ni}$ in the sample. Figure 2a shows typical a dark-field STEM image of an agglomerate of NiO and YSZ particles and Fig. 2b-d shows the spatial distribution of the Ni and Zr. Only a weak signal of Ni is observed in the area of the YSZ particles. Only areas that indicated a physical overlap of $\mathrm{NiO}$ and YSZ particles show stronger x-ray signals for both Ni and Zr. The analysis therefore shows a low degree of $\mathrm{NiO}$ incorporation in YSZ. Although incorporation of $\mathrm{NiO}$ into $\mathrm{YSZ}$ can partly explain a slower reduction of $\mathrm{NiO}$, the small amount of $\mathrm{Ni}$ in the YSZ grains according to the STEM-EDS analysis shows that this is not likely the main explanation for the relatively strong inhibitive effect observed from TGA. 


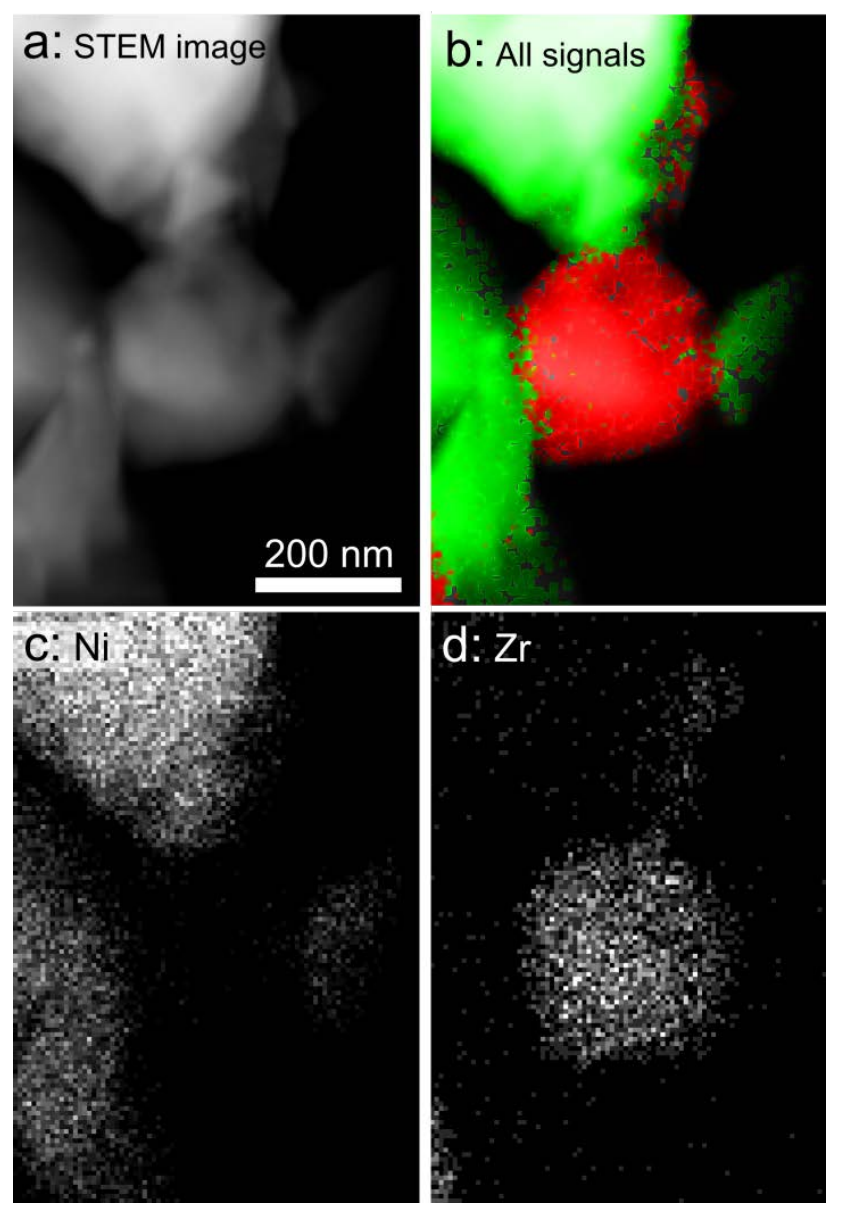

Fig. 2a-d: a) A HAADF STEM image, b) an elemental map (green $=\mathrm{Ni}$, red $=\mathrm{Zr}$ ), c) the spatial distribution of the Ni$\mathrm{K} \alpha$ EDS signal, d) the spatial distribution of the Zr-Ka EDS signal of the NiO/YSZ powder sample.

\subsection{Environmental TEM results}

Figure 3 presents the reduction of the pure $\mathrm{NiO}$ powder inside the ETEM. The sample is exposed to 2 mbar $\mathrm{H}_{2}$ while the temperature is ramped from $180^{\circ} \mathrm{C}$ by $1^{\circ} \mathrm{C} / \mathrm{min}$ as in the TGA experiment (Fig. 1). At the relatively low magnification in Fig. 3, the lattice planes are not resolved, as when acquiring the image at higher resolution (See Fig. A.2 in the supplementary materials). Instead it can be seen that the $\mathrm{NiO}$ particle is initially dense, but apparently becomes porous, consistent with previous reports where the reduced $\mathrm{Ni}$ was characterized by a porous morphology [17-19]. The dense areas are therefore interpreted as $\mathrm{NiO}$ and the porous areas as $\mathrm{Ni}$. For most of the recorded images series, the reduction was observed to initiate at several different sites at the NiO particles. The largest particle presented in Fig. 3 is a special case in the sense that the reduction initiated only at a few sites, e.g. at the site indicated by the arrow (Fig. 3b). It is observed that a front of porous $\mathrm{Ni}$ travels from the initial site over the $\mathrm{NiO}$ until the whole particle appears porous (See also the movie 
"Low mag reduction of pure NiO powder" in the supplementary materials). According to Fig. 3, the reduction rate is therefore highest near the NiO-Ni interface, which illustrates the previously suggested autocatalytic effect for the NiO reduction [10]. Fig. 3 also illustrates an advantage of the in situ method compared to post mortem TEM analysis. In one experiment we are able to follow the reduction process from onset to full reduction. To produce an image series with a comparable temperature/time resolution by a series of aging treatments in a furnace combined with post mortem characterization would be much more time consuming. The heating and cooling between each step in the aging may influence the results. Such possible irreversible effects are avoided by the in situ experiment.
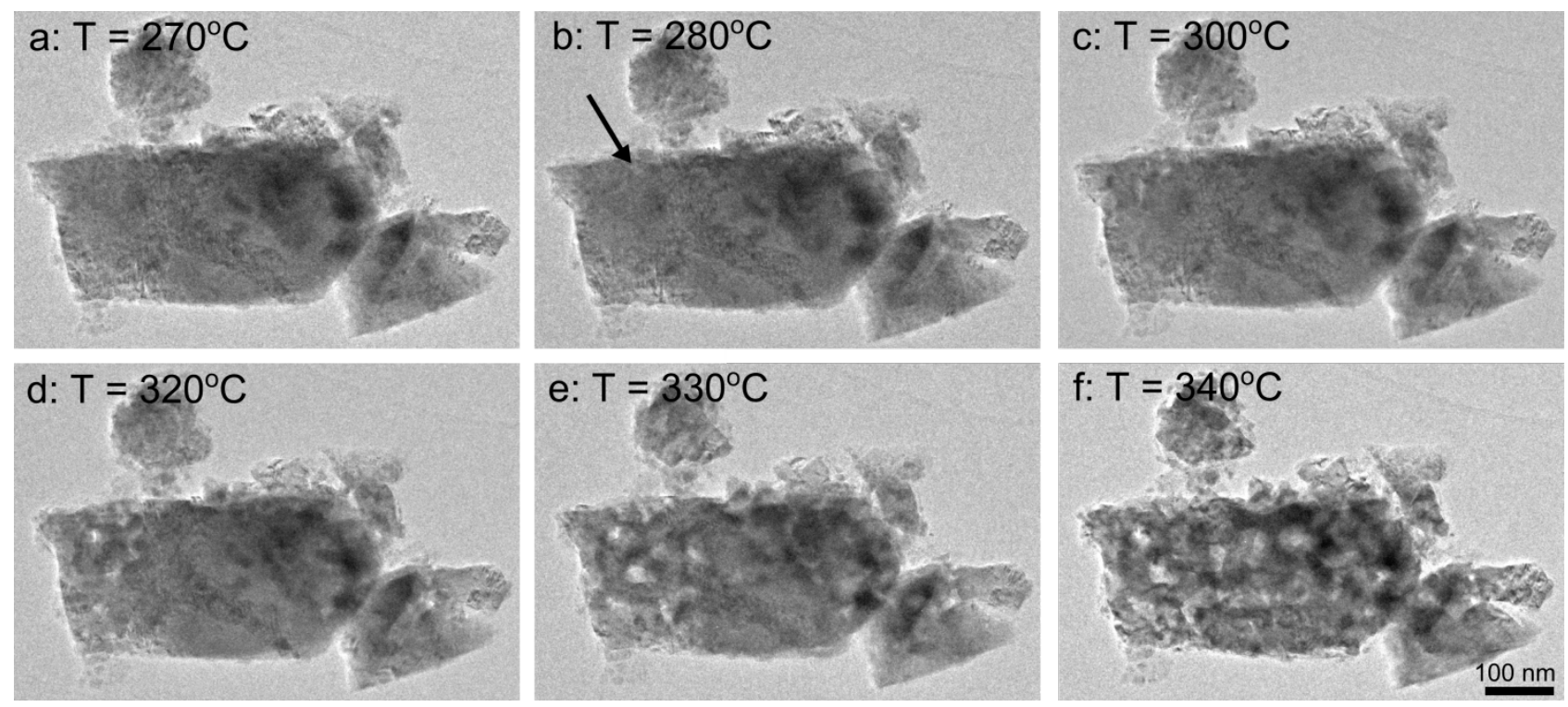

Fig. 3a-f: In situ TEM image series of the same region of the NiO powder sample during exposure to $2 \mathrm{mbar}^{\mathrm{H}_{2}}$ and constant temperature ramping rate of $1^{\circ} \mathrm{C} / \mathrm{min}$. To guide the eye, an arrow points to the site where close inspection reveals the first pore formation.

Figure 4 presents an ETEM image series of NiO/YSZ powder during exposure to 2 mbar $\mathrm{H}_{2}$ while ramping the temperature at $1^{\circ} \mathrm{C} / \mathrm{min}$ similar to the TGA experiment (Fig. 1) and to the in situ experiment for pure $\mathrm{NiO}$ (Fig. 3). As for the pure $\mathrm{NiO}$, the reduction process of $\mathrm{NiO}$ in $\mathrm{NiO} / \mathrm{YSZ}$ can be observed by the formation of a porous structure in the initially dense NiO (See also the movie "Low mag reduction of $\mathrm{NiO} / Y S Z$ powder" in the supplementary materials). To guide the eye the initial reduction sites are indicated in Fig. 4b. It is observed that the reduction process is initiated near both NiO-gas and NiO-YSZ interfaces. No significant difference in the initiation and progression of the porous $\mathrm{Ni}$ reaction fronts could be identified in $\mathrm{NiO}$ close to or far from the NiOYSZ interfaces. This result is representative of all six images series recorded of the NiO/YSZ 
powder. From Fig. 4 it can be seen that the developed porous structure of Ni densified as the temperature is increased above $400^{\circ} \mathrm{C}$. Densification of porous $\mathrm{Ni}$ at temperatures above $600^{\circ} \mathrm{C}$ has also been reported in a previous study on a $\mathrm{NiO}$ powder [26]. The observation is consistent with the suggested rule that metallic mobility in a hydrogen atmosphere is initiated approximately at the Tamman temperature, which for bulk $\mathrm{Ni}$ is $590^{\circ} \mathrm{C}$ [33].
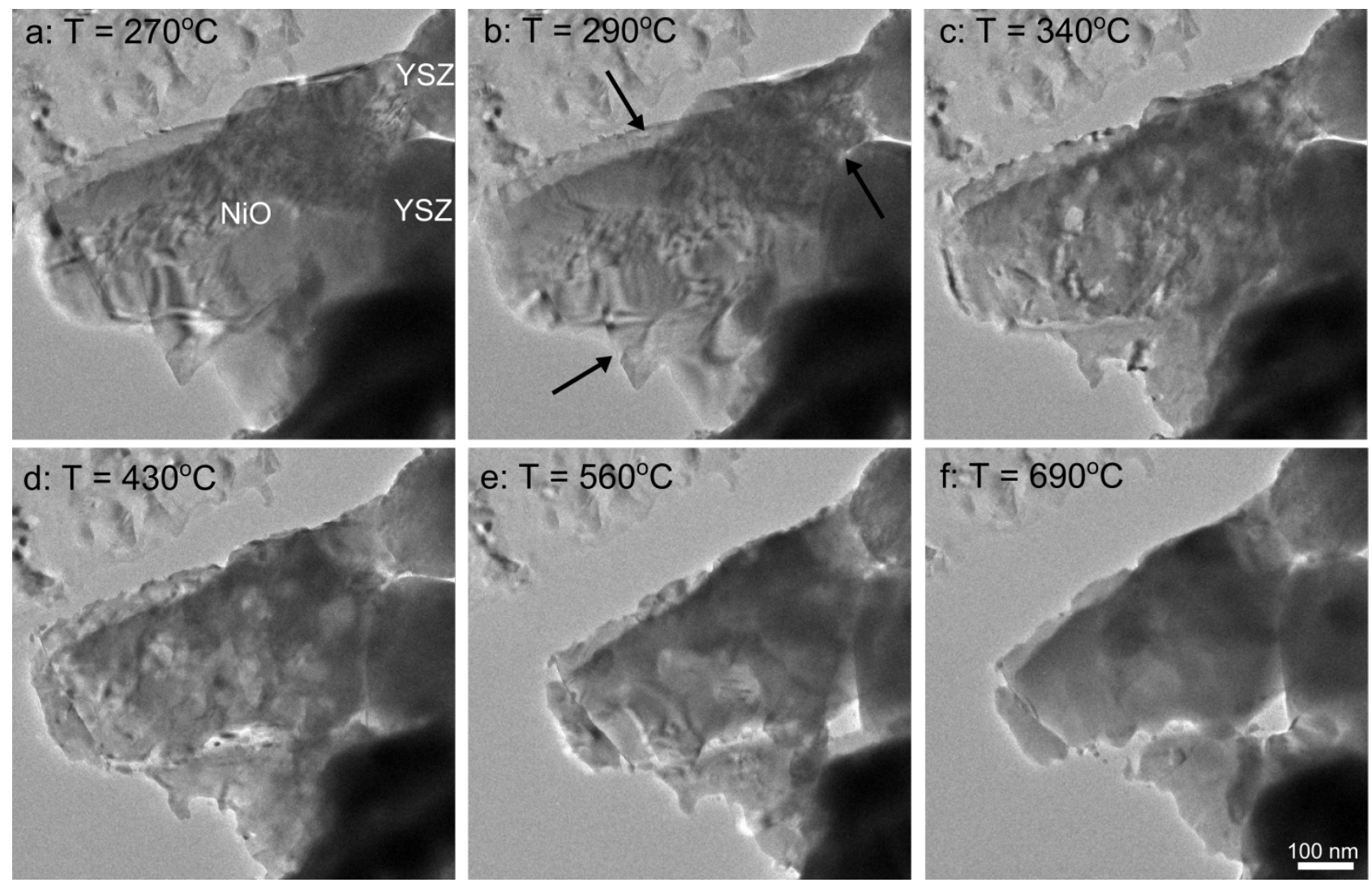

Fig. 4a-f: ETEM image series of the same region of the NiO/YSZ powder sample during exposure to $2 \mathrm{mbar}^{\mathrm{H}_{2}}$ and constant temperature ramping rate of $1^{\circ} \mathrm{C} / \mathrm{min}$. (a-c) presents the $\mathrm{NiO}$ reduction process. (d-f) presents the densification of reduced $\mathrm{Ni}$ at high temperatures. To guide the eye, an arrow points to the site where close inspection reveals the first pore formation.

In addition to ETEM image series, a series of electron diffraction patterns were recorded for each reduction experiment of $\mathrm{NiO}$ and $\mathrm{NiO} / \mathrm{YSZ}$ (See Fig. A.3 in the supplementary materials). Fig. 5a illustrates the detailed temperature dependence of the electron diffraction signal: Here the normalized peak intensity of the $\mathrm{NiO}$ signal is presented as a function of temperature for $\mathrm{NiO}$ powder (black squares) and $\mathrm{NiO} / \mathrm{YSZ}$ powder (grey squares). Comparison with the TGA data (NiO powder: black dashed line, $\mathrm{NiO} / \mathrm{YSZ}$ : grey dashed line) shows that the temperature dependence determined from TEM of both $\mathrm{NiO}$ and $\mathrm{NiO} / \mathrm{YSZ}$ matches the trend found from TGA for the pure 
$\mathrm{NiO}$ powder (Fig. 5a). A similar analysis performed on a $\mathrm{Ni}$ reflection (not presented) was consistent with the presented analysis for the $\mathrm{NiO}$ reflection.

To compare the image and diffraction analysis as a function of temperature, the porous areas (interpreted as reduced parts of the sample) were estimated and manually outlined by using the software ImageJ for three different $\mathrm{NiO}$ and $\mathrm{NiO} / \mathrm{YSZ}$ particles as a function of temperature. Figure 5b presents the normalized non-porous areas as a function of temperature for NiO powder (black squares) and $\mathrm{NiO}$ YYSZ powder (grey squares). As observed from the diffraction analysis (Fig. 5a), the temperature dependence of the reduction process of both $\mathrm{NiO}$ and $\mathrm{NiO} / \mathrm{YSZ}$ matches the trend found from TGA for the NiO powder (Fig. 5b). In other words, YSZ does not inhibit the reduction of the thin $\mathrm{NiO}$ and $\mathrm{NiO} / Y S Z$ TEM samples as it does for the macroscopic samples. Figure 5a-b also show that the image and diffraction analysis are consistent in the description of the temperature dependence of the reduction and verify that the pore formation is a good indicator of Ni formation.

a

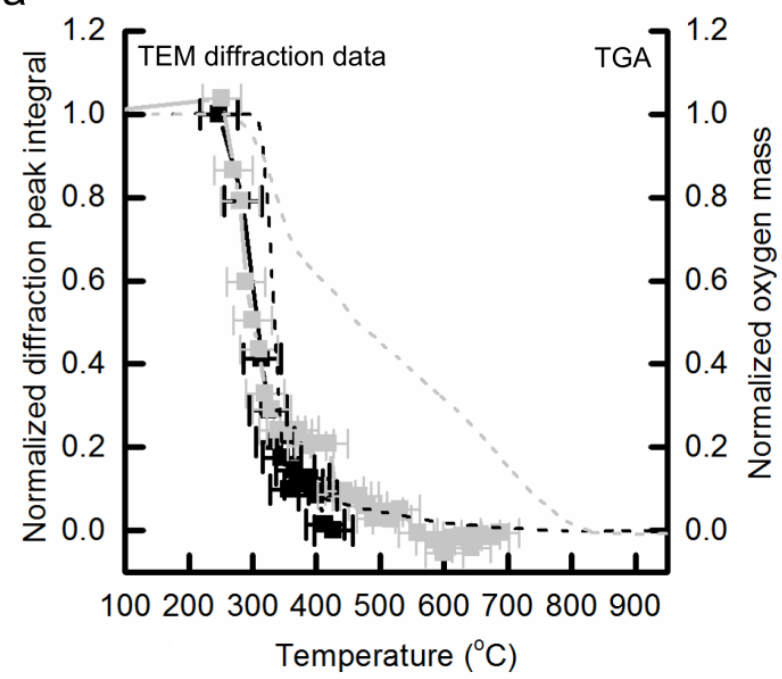

b

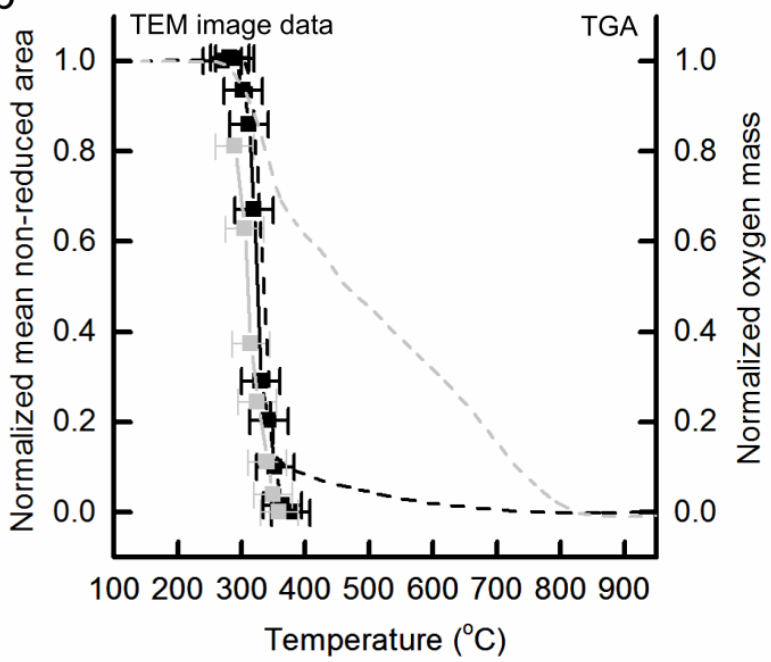


Fig. 5a-b: (a) Normalized electron diffraction peak integral for the $\mathrm{NiO}$ [440] peak for NiO powder (black squares) and $\mathrm{NiO} / \mathrm{YSZ}$ powder (grey squares) presented as a function of temperature. (b) The normalized mean area of non-reduced $\mathrm{NiO}$ for three grains from a $\mathrm{NiO}$ powder (black squares) and $\mathrm{NiO} / \mathrm{YSZ}$ powder (grey squares) presented as a function of temperature. For comparison, the TGA data of the normalized oxygen mass for NiO powder (black dotted line) and $\mathrm{NiO} /$ YSZ powder (grey dotted line) from Fig. 1 is presented. Error bars indicate the estimated errors on the temperature calibration.

In order to address the Ni mobility at high temperatures $\left(>400^{\circ} \mathrm{C}\right)$ as indicated in Fig. $4 \mathrm{~d}-\mathrm{f}$, an experiment was designed to study the reduction of $\mathrm{NiO} / \mathrm{YSZ}$ when exposed to $\mathrm{H}_{2}$ instantly at a realistic operation temperature near $800^{\circ} \mathrm{C}$. The ideal way of performing such an experiment would be to ramp the temperature to the operation temperature in an inert gas and record the response from the sample when $\mathrm{H}_{2}$ is introduced at the high temperature. To do this a new calibration of the TEM heating chip would be needed for the inert gas, and changing the gas composition in this way would, however, simultaneously influence the temperature of the sample. In practice, the NiO/YSZ powder was exposed to $\mathrm{H}_{2}$ at room temperature and the temperature was ramped to $780^{\circ} \mathrm{C}$ with the high ramping rate of $1000^{\circ} \mathrm{C} / \mathrm{s}$. In this way the environment is changed from non-reducing, to reducing at $780^{\circ} \mathrm{C}$ in $1 \mathrm{~s}$. Figure $6 \mathrm{a}-\mathrm{c}$ presents a TEM image series of the experiment. The first image (Fig. 6a) presents the sample in $\mathrm{H}_{2}$ at room temperature and the second image (recorded $2 \mathrm{~s}$ later) presents the sample in $\mathrm{H}_{2}$ at $780^{\circ} \mathrm{C}$. The figure shows that the sample structure changes abruptly during the short reduction time and that only slower changes take place after the first $2 \mathrm{~s}$ for the nanoscaled structure (Fig. 6b-c). None or only minor sample porosity is observed and the sample appears to directly transform into the dense state. Therefore it is not possible from the image series to uniquely identify the location of the NiO and the YSZ particles, except by assuming that only the shape of the Ni and not the YSZ particles are changed at this temperature. 

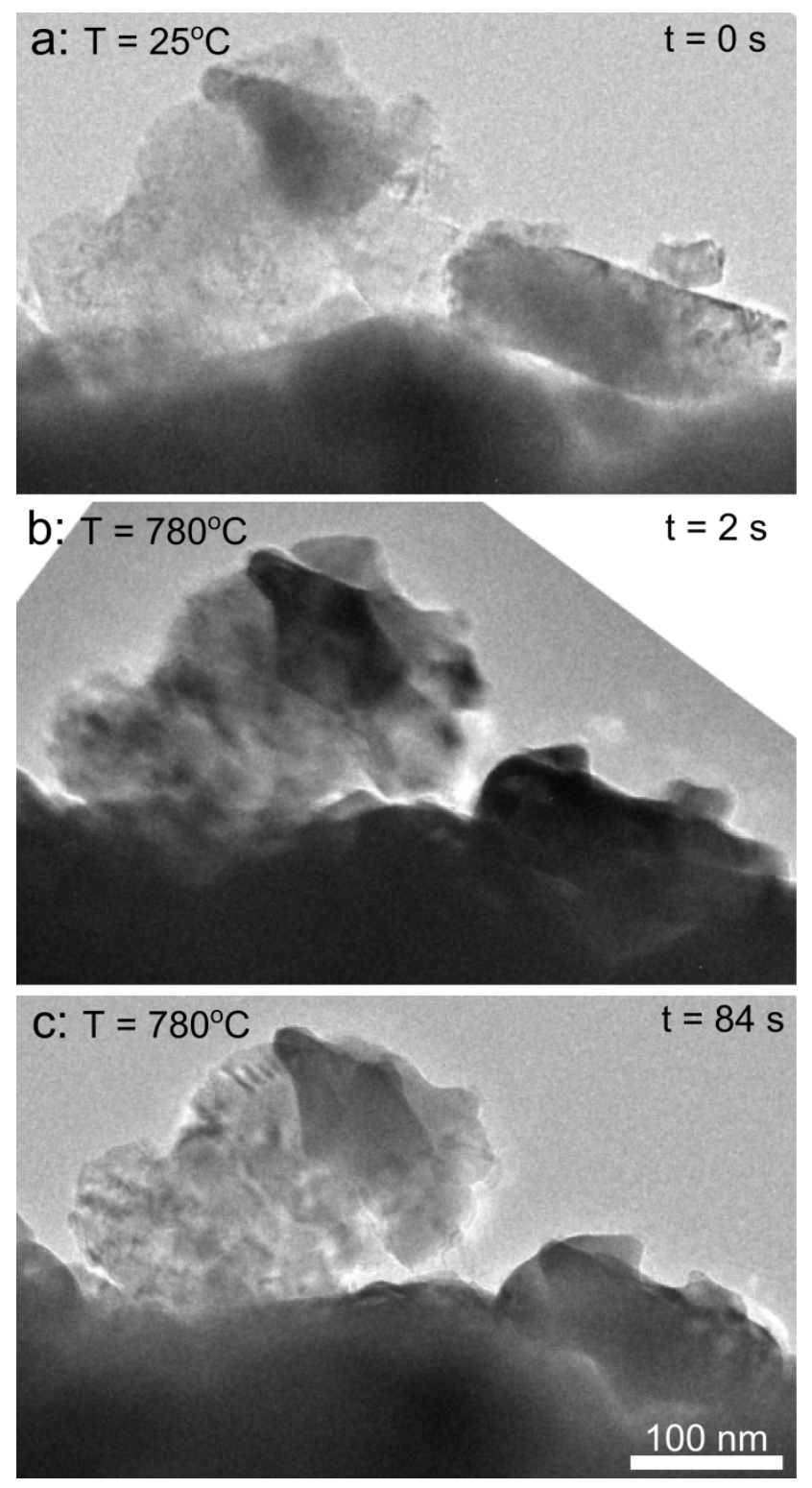

Fig. 6a-c: In situ TEM image series of the same region of the NiO/YSZ powder during exposure to 2 mbar $\mathrm{H}_{2}$. The temperature is ramped by $1000^{\circ} \mathrm{C} / \mathrm{s}$ between image (a) and (b) and held constant hereafter. The time of the image acquisition and the temperature is indicated in each image. The dark contrast of the sample in (b) relative to (a, c) is due to an abrupt change in focus during temperature ramping, which was adjusted in (c).

\section{Discussion}

According to the TGA results, the reduction reaction of $\mathrm{NiO}$ with $\mathrm{H}_{2}$ is generally slower for $\mathrm{NiO} / Y S Z$ powder or dense samples compared to the reduction of pure NiO powders (Fig. 1). This result is consistent with results from previous studies where it was suggested that YSZ has an inhibitive effect on the $\mathrm{NiO}$ reduction $[11,12,16]$. The samples from references $[12,16]$ are relatively comparable to the present samples ([16]: dense samples prepared by mixing 60 mol\% 
$\mathrm{NiO} / \mathrm{YSZ}$ with $8 \mathrm{~mol} \%$ yttria, die pressed and sintering in air, at temperatures of $1400^{\circ} \mathrm{C}$ or $1600^{\circ} \mathrm{C}$ for 2 or 8 hours respectively, [12]: dense or powder samples prepared by mixing 65 mol\% $\mathrm{NiO} / \mathrm{YSZ}$ with $8 \mathrm{~mol} \%$ yttria, die pressed and sintering in air, at temperatures of $1200-1400^{\circ} \mathrm{C}$ for 5 hours). It has been suggested that the $\mathrm{NiO}$ reduction is inhibited directly by YSZ at or near the $\mathrm{NiO} / \mathrm{YSZ}$ interface, e.g. via strong NiO-YSZ chemical interaction [16] or due to slow Ni nucleation at the NiO-YSZ interface [12]. Such direct NiO-YSZ interactions as well as mass/gas transport limitations are likely to influence the $\mathrm{NiO}$ reduction rate, but the degree of influence from these different phenomena is still not clear. It is therefore interesting that no inhibitive effect is observed with ETEM (Fig. 5), but only with TGA for the same type of sample (Fig. 1) in the present study. Also, in a recent ETEM study of a dense planar NiO/YSZ sample, which was thinned by a focused ion beam, the inhibitive effect from YSZ on NiO reduction was not observed [19]. This study even suggests that the $\mathrm{NiO}$ reduces slightly faster at a NiO-YSZ interface than at a NiO-gas phase interface, but this could not be observed in the present ETEM experiments (Fig. 4 and Fig. 5). It is important to note that the results from studies of macroscopic samples are influenced by e.g. mass and gas transport limitations depending on the structure of the three-dimensional network of NiO, YSZ and pores in the sample. On the contrary, TEM samples do not form such a three-dimensional framework, but are almost two-dimensional with a thickness up to only a few hundred nanometers where each particle has access to the gas phase. It can therefore be expected that mass and gas transport limitation will only have minor influence on the reaction rates observed from ETEM. This could indicate that the inhibitive effect of YSZ on the NiO reduction observed from TGA is mainly due to limitations of mass and/or gas transport.

It should be emphasized that the comparison of the present results with previous works may be partly hampered by the variations in SOFC/SOEC sample preparation since there is no universal standard cell material. Therefore NiO-YSZ-gas phase interactions could be influenced by such sample variations. For example the gas and mass transport is obviously different for powders and dense samples and higher sintering temperatures may lead to a higher degree of chemical NiO-YSZ interactions or to a higher degree of nickel incorporation in YSZ as for example observed in reference [31].

Besides presenting the reduction process of $\mathrm{NiO} / \mathrm{YSZ}$ at the nanoscale, the ETEM experiments also show that the $\mathrm{Ni}$ is mobile at temperatures above ca. $400^{\circ} \mathrm{C}$ (Fig. 4). A high mobility was observed at $780^{\circ} \mathrm{C}$, which is close to the normal operating temperature a solid oxide fuel or electrolysis cell 
(Fig. 6). This suggests that the electrochemically active structures of the operating cell, the so-called triple phase boundaries between Ni (solid), YSZ (solid) and $\mathrm{H}_{2}$ (gas), are dynamic at the nanoscale. The structure of the triple phase boundaries can therefore be expected to change during the lifetime of the cells leading to activation or more likely to deactivation depending on the developed structure.

The results from Fig. 6 also suggest that the reduction process near $800^{\circ} \mathrm{C}$ of an industrial SOFC (SOEC), will lead to immediate collapse of any Ni nanopores to form dense Ni particles. The larger micro-pores formed from the volume loss of oxygen during the reduction are, however maintained. This is partially due to the structure of YSZ, which is not changed by the reduction process [11], but even for initially dense samples of pure $\mathrm{NiO}$, micro-porosity is observed after reduction in $100 \% \mathrm{H}_{2}$ at temperatures as high as $1000^{\circ} \mathrm{C}$ and the pore sizes increase with the reduction temperature $[17,18]$. Hidayat et al. found that at temperatures up to $600^{\circ} \mathrm{C}$, $\mathrm{NiO}$ reduction was well-described by kinetics limited by the chemical reaction at the Ni-NiO interface contrary to kinetics limited by gas transport [18]. At higher temperatures the observed reaction rate was lower than suggested by the kinetic interface-limited model and a lower overall reaction rate was even observed at $600-800^{\circ} \mathrm{C}$ compared to the lower temperatures $[17,18]$. The authors suggest that this is related to the temperature dependent pore sizes, by a transition from the interface-limited reaction to kinetics limited by solid state diffusion of Ni cations in the NiO [18]. The conclusion was based on a model, which does not take the observed dynamical morphological changes of the Ni (Fig. 4, Fig. 6) into account. The present results suggest the alternative explanation that the larger pore sizes observed at high temperatures are due to collapse of the Ni nanopores and coarsening of the Ni particles (fig 4, Fig. 6). It is well-known that gas diffusion rates depend on the pore sizes, and such a structural change will therefore influence the overall reaction rates [34]. Besides changing the Ni pore structure, the mobility of the Ni could also lead to a high coverage of $\mathrm{Ni}$ on the NiO surface and thereby lower the access of the gas phase to the active sites. Further investigations are needed to determine if this is the case at the micro-scale during reduction in dry $\mathrm{H}_{2}$. It has, however, already been reported, that a fully dense $\mathrm{Ni}$ layer can be created on top of $\mathrm{NiO}$, by reducing at a high temperature while slowing down the reduction process by using a low $\mathrm{H}_{2}$-to- $\mathrm{H}_{2} \mathrm{O}$ ratio feed gas. After formation of the dense Ni layer, the reaction process slowly proceeds via diffusion of hydrogen through the $\mathrm{Ni}[18]$. 
It should be emphasized that the model SOFC anode (SOEC cathode) used in the ETEM experiments in some respects will deviate from industrial anodes (cathodes). As described in detail in the methods section, the $\mathrm{NiO}$ /YSZ powder sample is not simply a mixture of $\mathrm{NiO}$ and YSZ powders, but is prepared from a sintered dense ceramic SOFC anode (SOEC cathode), which was thinned for TEM by breaking the sample into small agglomerates. As discussed above the mass and gas transport during reduction for such a ceramic powder sample can be expected to be different than compared to the initial dense ceramic. Figure 1 compares the reduction profiles for the powder (solid grey) and dense (dashed grey) $\mathrm{NiO} / Y S Z$, illustrating that the profiles indeed are different. It may be surprising to observe that the difference is mainly a shift in onset temperature, while similar reduction profiles are observed in the high temperature range from about $500^{\circ} \mathrm{C}$ and up. Several reasons for the temperature shift can be suggested: The preparation step of grinding the dense sample into powder will for example introduce additional defects at the $\mathrm{NiO}$ surfaces. As described in the introduction, the incubation period for $\mathrm{NiO}$ reduction scales with the number of $\mathrm{NiO}$ surface defects. Also, the powder sample has a significantly higher NiO surface area exposed directly to the gas phase. Further studies are needed to determine the most important reasons. When comparing the reduction of nanoscaled ceramic powder samples with industrial SOFC anodes (SOEC cathodes) these differences should therefore be taken into account.

It should also be mentioned that despite the difference in the $\mathrm{H}_{2}$ pressure of almost a factor of 50 in the ETEM experiment compared to the TGA experiment, the reduction onset temperature of the $\mathrm{NiO}$ powders did not shift. This may seem surprising when taking into account the previously reported dependence of the reaction rate on the $\mathrm{H}_{2}$ partial pressure $[8,10,17]$. These reports are, however, based on comparison of different pressure regimes $\left(10^{-7}-7\right.$ mbar $[8,10]$ and $260-1000$ mbar [17]) and may not be comparable to the present conditions. An additional TGA experiment was performed for the non-sintered $\mathrm{NiO}$ powder sample in $0.2 \% \mathrm{H}_{2} / \mathrm{N}_{2}$, comparable to the $\mathrm{H}_{2}$ partial pressure in the ETEM experiment and with slow temperature ramping of $0.1{ }^{\circ} \mathrm{C} / \mathrm{min}$. Also for this experiment the temperature onset for $\mathrm{NiO}$ reduction was ca. $300^{\circ} \mathrm{C}$ (not presented).

\section{Conclusions}

The reduction process of $\mathrm{NiO}$ and $\mathrm{NiO} / \mathrm{YSZ}$ was investigated by the comparison of results from ETEM and TGA. The TGA results showed the inhibitive effect from YSZ. ETEM images and the diffraction series revealed nanoscaled pore formation of $\mathrm{NiO}$ and $\mathrm{NiO} / \mathrm{YSZ}$ during the reduction above $280^{\circ} \mathrm{C}$. It was also found that the inhibitive effect from YSZ is not due to a direct local 
interaction between $\mathrm{NiO}$ and YSZ. Instead it is suggested that the effect results from gas and/or mass transport limitations in the complex three-dimensional structure of the SOFC anode/SOEC cathode. These limitations may be taken into account when designing new reduction procedures for optimizing the performance of the electrochemical cells. It may also be taken into account that the reduced $\mathrm{Ni}$ was observed to be mobile at temperatures above $400^{\circ} \mathrm{C}$ and rapid mobility at the nanoscale was observed near normal operation temperatures for an industrial SOFC/SOEC. This means that the nanoscaled three-dimensional structures of an SOFC/SOEC can vary significantly depending on the reduction and operation temperatures. Specifically, nanoporosity in the $\mathrm{Ni}$ particles will decay for temperatures above $400^{\circ} \mathrm{C}$. The observed Ni mobility also confirms that electrochemical cells suffer from deactivation due to coarsening of $\mathrm{Ni}$ at the triple-phase boundaries.

\section{Acknowledgements}

Karen Brodersen, DTU Energy Conversion is acknowledged for tape casting of the SOFC/SOEC samples. Lene Knudsen, DTU Energy Conversion is acknowledged for XRD measurements. Carsten Gynther Sørensen, DTU Energy Conversion is acknowledged for performing the TGA experiments.

The A.P. Møller and Christine Mc-Kinney Møller Foundation is gratefully acknowledged for their contribution toward the establishment of the Center for Electron Nanoscopy in the Technical University of Denmark.

\section{References}

1. H. Knozinger, E. Taglauer, in: G. Ertl, H. Knözinger, J. Weitkamp (Eds), Handbook of Heterogeneous Catalysis, vol. 3, Wiley-VCH, New York, 1997, pp. 216-231.

2. B. Delmon, in: G. Ertl, H. Knözinger, J. Weitkamp (Eds), Handbook of Heterogeneous Catalysis, vol. 3, Wiley-VCH, New York, 1997, pp. 264-285.

3. V.R. Choudhary, A.M. Rajput, A.S. Mamman, J. Catal. 178 (1998) 576-585.

4. L.A. Bruce, J.F. Mathews, Appl. Catal. 4 (1982) 353-370.

5. S.B. Simonsen, D. Chakraborty, I. Chorkendorff, S. Dahl. Appl. Catal. A-Gen, 447- 448 (2012) $22-31$. 
6. A.F. Benton, P.H. Emmett, J. Am. Chem. Soc. 46 (1924) 2728-2737.

7. G. Parravano, J. Am. Chem. Soc. 74 (1952) 1194-1198.

8. R.P. Furstenau, G. McDougall, M.A. Langell, Surf. Sci. 150 (1985) 55-79.

9. E.C. Dickey, V.P. Dravid, P.D. Nellist, D.J. Wallis, S.J. Pennycook, A. Revcolevschi, Microsc. Microanal. 3 (1997) 443-450.

10. J.A. Rodriguez, J.C. Hanson, A.I. Frenkel, J.Y. Kim, M. Perez, J. Am. Chem. Soc. 124 (2002) 346-354.

11. H. Mori, C. Wen, J. Otomo, K. Eguchi, H. Takahashi, Appl. Catal. A-Gen. 245 (2003) 79-85.

12. D. Fouquet, A.C. Müller, A. Weber, E. Ivers-Tiffée, Ionics 8 (2003) 103-108.

13. N.M. Tikekar, T.J. Armstrong, A.V. Virkar, in: S.C. Singhal, M. Dokiya (Eds), Electrochemical Society Proceedings vol. 2003-07, The Electrochemical Society Inc., Pennington, 2003, pp. 670679.

14. D. Waldbillig, A. Wood, D.G. Ivey, Solid State Ionics 176 (2005) 847-859.

15. A. Hagen, H.F. Poulsen, T. Klemensø, R.V. Martins, V. Honkimäki, T. Buslaps, R. Feindenhans'l, Fuel Cells 5 (2005) 361-366.

16. N.M. Tikekar, T.J. Armstrong, A.V. Virkar, J. Electrochem. Soc. 153 (2006) A654-A663.

17. T. Hidayat, M.A. Rhamdhani, E. Jak, P.C. Hayes, Metall. Mater. Trans. B 40B (2009) 1-16.

18. T. Hidayat, M.A. Rhamdhani, E. Jak, P.C. Hayes, Metall. Mater. Trans. B 40B (2009) 474-489.

19. Q. Jeangros, A. Faes, J.B. Wagner, T.W. Hansen, U. Aschauer, J. Van Herle, A. Hessler-Wyser, R.E. Dunin-Borkowski, Acta Mater. 58 (2010) 4587-4589.

20. S.L. Ebbehøj, T. Ramos, M. Mogensen, ECS Trans. 45 (2012) 363-375.

21. R.T.K. Baker, P.S. Harris, J. Phys. E Sci. Instrum. 5 (1972) 793-797.

22. R. Sharma, P.A. Crozier, in: N. Yao, Z.L. Wang (Eds.), Handbook of Microscopy for Nanotechnology, Klüwer Academic Publishers, Boston/Dordrecht/New York/London, 2005, pp 531-565. 
23. P.L. Hansen, S. Helveg, A. Datye, Adv. Catal. 50A (2006) 77-94.

24. B. Wagner, F. Cavalca, C.D. Damsgaard, L.D.L. Duchstein, T.W. Hansen, Micron 43 (2012) 1169-1175.

25. S. Chenna, R. Banerjee, P.A. Crozier, Chem. Cat. Chem. 3 (2011) 1051-1059.

26. Q. Jeangros, T.W. Hansen, J.B. Wagner, C.D. Damsgaard, R.E. Dunin-Borkowski, C. Hébert, J. Van Herle, A. Hessler-Wyser, $10^{\text {th }}$ European SOFC Forum proceedings (2012) B0503.

27. S. Chenna, P.A. Crozier, Micron 43 (2012) 1188-1194.

28. R. Banerjee. P.A. Crozier, J. Phys. Chem. C 116 (2012) 11486-11495.

29. S. Ramousse, M. Menon, K. Brodersen, J. Knudsen, U. Rahbek, P.H. Larsen, ECS Trans. 7 (2007) 317-327.

30. T.W. Hansen, J.B. Wagner, R.E. Dunin-Borkowski, Mater. Sci. Technol. 26 (2010) 1338-1344.

31. D.L. King, J.J. Strohm, X. Wang, H.-S. Roh, C. Wang, Y.-H. Chin, Y. Wang, Y. Lin, R. Rozmiarek, P. Singh, J. Catal. 258 (2008) 356-365.

32. A. Kuzjukevics, S. Linderoth, Solid State Ionics 93 (1997) 255-261.

33. R.T.K. Baker, J. Catal. 78 (1982) 473-476.

34. J.M. Thomas, W.J. Thomas, Principles and practice of heterogeneous catalysis, VCH, Weinheim, 1997, pp. 290-314.

\section{List of figure captions}

Fig. 1: The mass as a function of temperature for non-sintered NiO powder (solid black), NiO powder ground after sintering at $1350^{\circ} \mathrm{C}$ (dashed black), $\mathrm{NiO} / \mathrm{YSZ}$ powder ground after sintering at $1350^{\circ} \mathrm{C}$ (solid grey), a dense piece of the $\mathrm{NiO} / \mathrm{YSZ}$ sintered at $1350^{\circ} \mathrm{C}$ (dashed grey) and $\mathrm{YSZ}$ powder ground after sintering at $1350^{\circ} \mathrm{C}$ (black dash-dot) during exposure to $9 \% \mathrm{H}_{2} / \mathrm{N}_{2}$ at a constant ramping rate of $1^{\circ} \mathrm{C} / \mathrm{min}$.

Fig. 2a-d: a) A HAADF STEM image, b) an elemental map (green $=\mathrm{Ni}$, red $=\mathrm{Zr}$ ), c) the spatial distribution of the Ni-Ka EDS signal, d) the spatial distribution of the Zr-Ka EDS signal of the $\mathrm{NiO} / Y S Z$ powder sample. 
Fig. 3a-f: In situ TEM image series of the same region of the NiO powder sample during exposure to 2 mbar $\mathrm{H}_{2}$ and constant temperature ramping rate of $1^{\circ} \mathrm{C} / \mathrm{min}$. To guide the eye, an arrow points to the site where close inspection reveals the first pore formation.

Fig. 4a-f: ETEM image series of the same region of the NiO/YSZ powder sample during exposure to 2 mbar $\mathrm{H}_{2}$ and constant temperature ramping rate of $1^{\circ} \mathrm{C} / \mathrm{min}$. (a-c) presents the $\mathrm{NiO}$ reduction process. (d-f) presents the densification of reduced Ni at high temperatures. To guide the eye, an arrow points to the site where close inspection reveals the first pore formation.

Fig. 5a-b: (a) Normalized electron diffraction peak integral for the NiO [440] peak for NiO powder (black squares) and NiO/YSZ powder (grey squares) presented as a function of temperature. (b) The normalized mean area of non-reduced $\mathrm{NiO}$ for three grains from a $\mathrm{NiO}$ powder (black squares) and $\mathrm{NiO} / Y S Z$ powder (grey squares) presented as a function of temperature. For comparison, the TGA data of the normalized oxygen mass for $\mathrm{NiO}$ powder (black dotted line) and NiO/YSZ powder (grey dotted line) from Fig. 1 is presented. Error bars indicate the estimated errors on the temperature calibration.

Fig. 6a-c: In situ TEM image series of the same region of the $\mathrm{NiO} / \mathrm{YSZ}$ powder during exposure to 2 mbar $\mathrm{H}_{2}$. The temperature is ramped by $1000^{\circ} \mathrm{C} / \mathrm{s}$ between image (a) and (b) and held constant hereafter. The time of the image acquisition and the temperature is indicated in each image. The dark contrast of the sample in (b) relative to (a, c) is due to an abrupt change in focus during temperature ramping, which was adjusted in (c).

\section{Appendix A. Supplementary material}

\section{ETEM movies}

"Low mag reduction of pure $\mathrm{NiO}$ powder"

The movie shows the same region of the $\mathrm{NiO}$ powder sample during exposure to $2 \mathrm{mbar}_{2}$ and constant temperature ramping rate of $1^{\circ} \mathrm{C} / \mathrm{min}$. The temperature is indicated in each frame.

“Low mag reduction of NiO/YSZ powder”

The movie shows the same region of the NiO/YSZ powder sample during exposure to 2 mbar $\mathrm{H}_{2}$ and constant temperature ramping rate of $1^{\circ} \mathrm{C} / \mathrm{min}$. The temperature is indicated in each frame.

Temperature calibration of the ETEM heating chips 
The temperature in the gas environment was calibrated using melting points of Zn nanoparticles (diameter $=$ ca. 100-300 nm, melting point is approximately equal to the bulk melting point of ca. $420^{\circ} \mathrm{C}$ [L. Gunawan, G.P. Johari, J. Phys. Chem. C 112 (2009) 20159-20166]) and Ag nanoparticles (diameter $=$ ca. $20 \mathrm{~nm}$, melting point ca. $900^{\circ} \mathrm{C}$ [W. Luo, W. Hu, S. Xiao, J. Phys. Chem. C 112 (2008) 2359-2369.]) dispersed on E-chips with a SiN support film. Here the temperature was ramped in steps of $25^{\circ} \mathrm{C}$ by $50^{\circ} \mathrm{C} / \mathrm{s}$ and for each step maintained constant for 2 min to record an electron powder diffraction pattern of the sample. The melting point was determined by the disappearance of diffraction spots with an estimated error of $25^{\circ} \mathrm{C}$, and it was verified that the spots returned when the temperature was lowered below the melting point. The melting points were also determined for the two metals in vacuum $\left(10^{-6} \mathrm{mbar}\right)$ and were found to correspond to the reference melting points for the metal nanoparticles, thereby verifying the initial calibration from the supplier. The resulting temperature calibration curve is based on a polynomial fit to three points (the melting points for $\mathrm{Zn}$ and $\mathrm{Ag}$ and additionally the point at room temperature) (Fig. A.1).

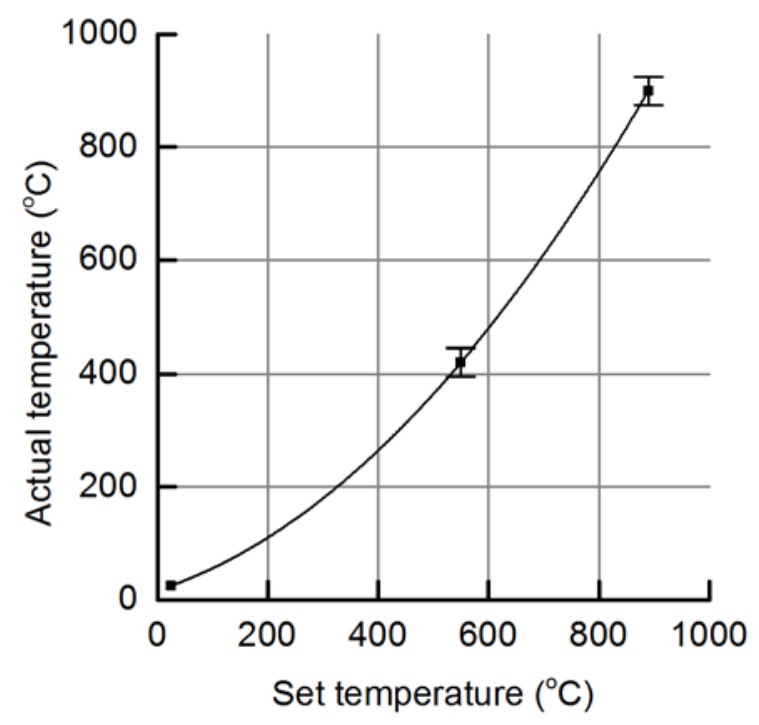

Fig. A.1: The actual temperature in 2 mbar $\mathrm{H}_{2}$ of the MEMS electrical TEM heating chip is presented as a function of the set temperature. The equation for the polynomial fit is: $7.6 \cdot 10^{-4} \mathrm{x}^{2}+0.31 \mathrm{x}+16.7$.

\section{In situ HRTEM}

Figure A.2a-f presents a HRTEM image series of the NiO/YSZ powder during exposure to 2 mbar $\mathrm{H}_{2}$ at the constant temperature of $320^{\circ} \mathrm{C}$. Crystals of $\mathrm{NiO}$ and $\mathrm{Ni}$ were identified in the HRTEM images from the characteristic lattice plane distances for the two phases as indicated in the figure 
(Fig. A.2a-f). In addition to $\mathrm{Ni}$ and $\mathrm{NiO}$, sheets of graphitic carbon are also observed on the surface of one of the Ni crystals and identified from the characteristic lattice spacing for graphite (Fig. A.2a-f). Carbon formation on Ni catalysts is a well-known phenomenon [See for example E.G.M. Kuijpers, J.W. Geus, Fuel 62 (1983) 158-161.]. The carbon is present on the sample since the samples were exposed to air prior to the ETEM analysis. In addition, the image series shows that the growth of $\mathrm{Ni}$ crystals is accompanied by shrinkage of the $\mathrm{NiO}$ crystals. The observations are consistent with a reduction process of $\mathrm{NiO}$ into pure $\mathrm{Ni}$.
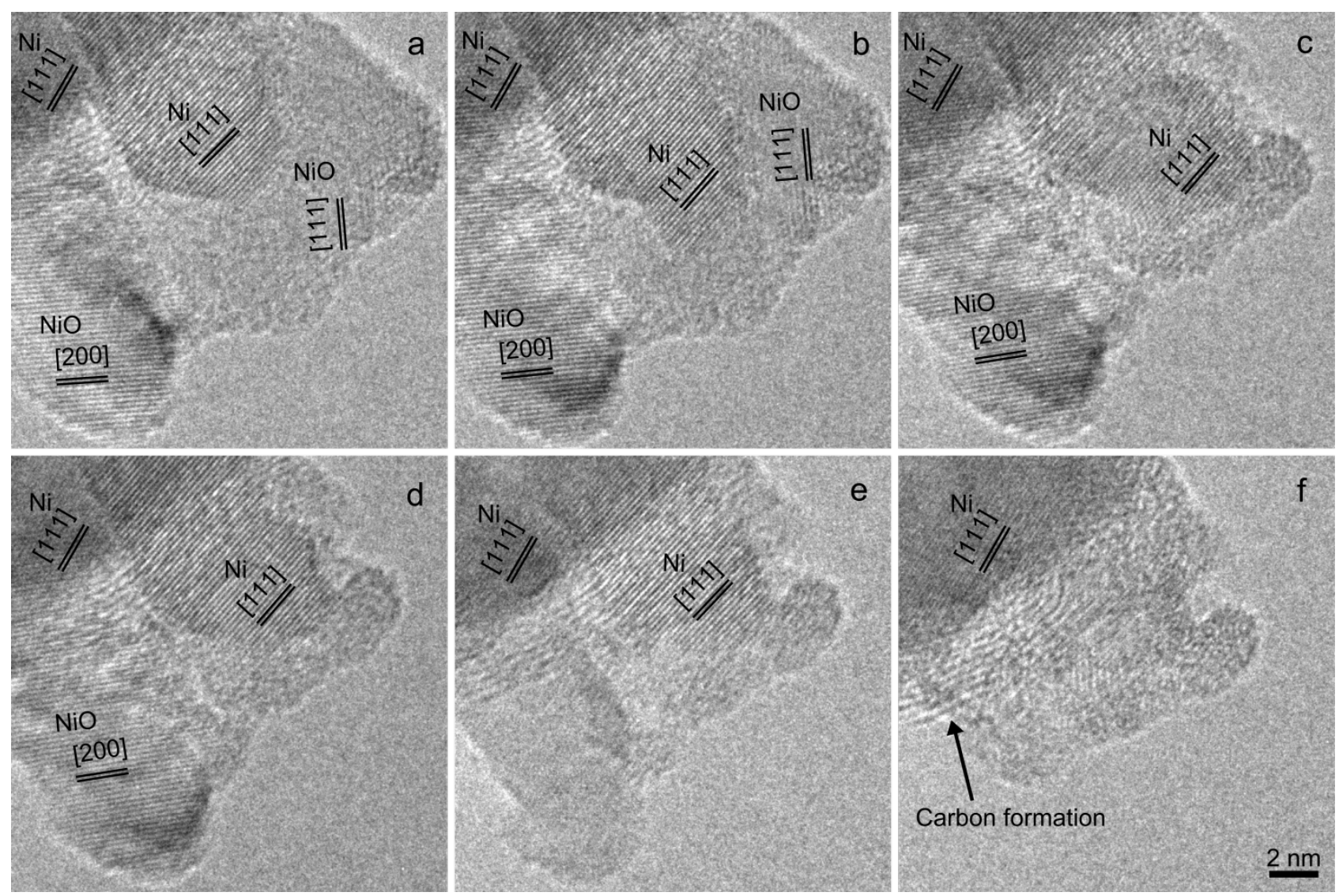

Fig. A.2a-f: In situ HRTEM image series of the same region of a NiO/YSZ powder sample during exposure to 2mbar $\mathrm{H}_{2}$ at $320^{\circ} \mathrm{C}$. The waiting time between each image is 10 s. Identified lattice distances for $\mathrm{Ni}$ and $\mathrm{NiO}$ are indicated. Carbon formation at the Ni surface is seen in all images (a-f) and its location is indicated in (f).

\section{ETEM electron powder diffraction}

Examples of powder diffraction images recorded during the ETEM reduction of $\mathrm{NiO}$ and $\mathrm{NiO} / \mathrm{YSZ}$ are presented by Fig. A.4. The diffraction patterns were recorded during the same experiments as those presented by Fig. 5 and fig 6. As indicated in the Fig. A.3, the patterns recorded at room 
temperature resemble the $\mathrm{NiO}$ phase for both samples (Fig. A.3a,c) and the patterns recorded at $650^{\circ} \mathrm{C}$ in $\mathrm{H}_{2}$ resemble the $\mathrm{Ni}$ phase for both samples (Fig. A.3b,d).

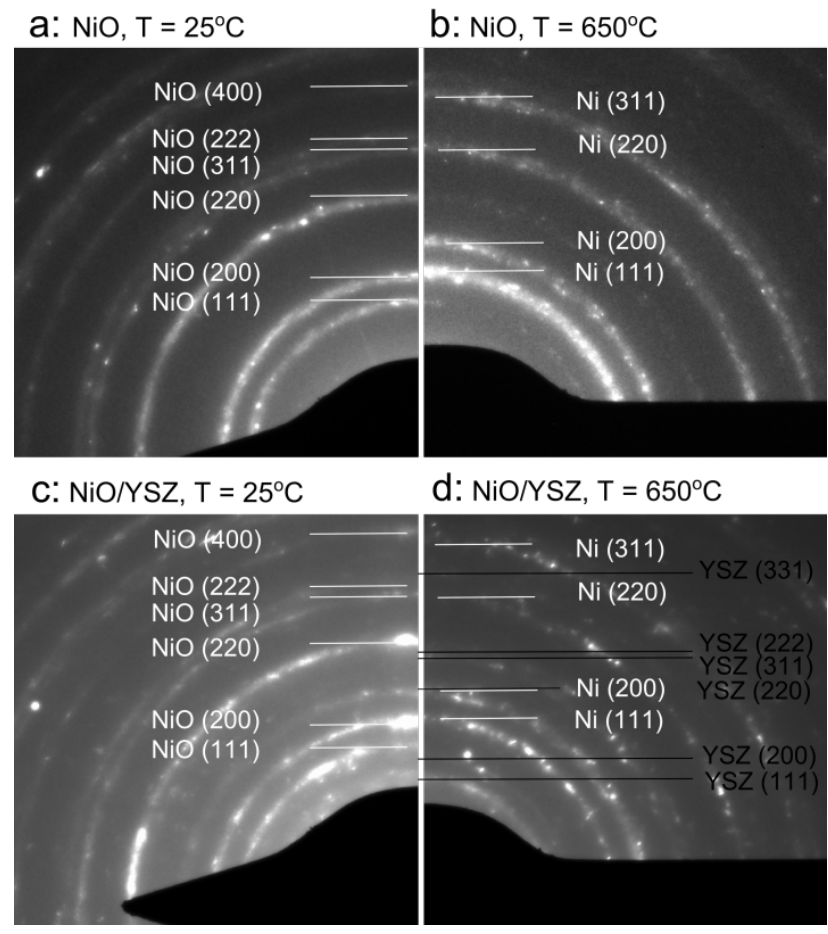

Fig. A.3a-d: Diffraction patterns recorded over the relatively large region of ca. $4 \mu \mathrm{m}^{2}$ during exposure to $2 \mathrm{mbar} \mathrm{H}_{2}$ for (a-b) $\mathrm{NiO}$ powder and for (b-c) $\mathrm{NiO} / \mathrm{YSZ}$ powder at the temperature of (a,c) $25^{\circ} \mathrm{C}$ and (c,d) $560^{\circ} \mathrm{C}$. Reference distances for $\mathrm{Ni}, \mathrm{NiO}$ and $\mathrm{YSZ}$ lattice planes are indicated.

$X$-ray diffraction $(X R D)$

XRD measurements were performed on the powder samples on a Bruker D8 Advance

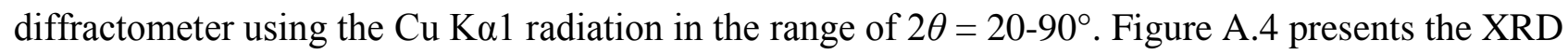
results. The patterns show that the $\mathrm{NiO}$ phase in the $\mathrm{NiO} / \mathrm{YSZ}$ is identical to that of pure $\mathrm{NiO}$ and that the YSZ phase in the NiO/YSZ is identical to that of pure YSZ. The NiO and YSZ patterns also match reference spectra (not presented) for the two pure phases. 


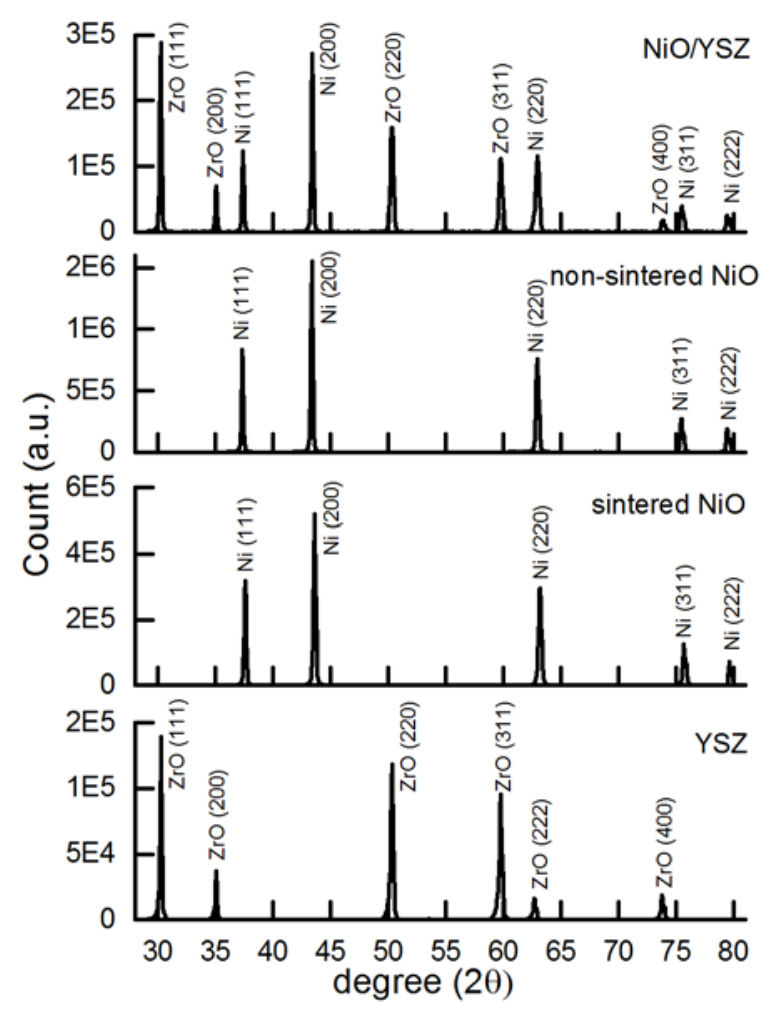

Fig. A.4: XRD spectra of the non-sintered $\mathrm{NiO}$ powder, $\mathrm{NiO}$ powder ground after sintering at $1350^{\circ} \mathrm{C}, \mathrm{NiO} / \mathrm{YSZ}$ powder ground after sintering at $1350^{\circ} \mathrm{C}$ and $\mathrm{YSZ}$ powder ground after sintering at $1350^{\circ} \mathrm{C}$. 